\title{
Organelle targeting: third level of drug targeting
}

\author{
This article was published in the following Dove Press journal: \\ Drug Design, Development and Therapy \\ 16 July 2013 \\ Number of times this article has been viewed
}

\author{
Niraj M Sakhrani \\ Harish Padh \\ Department of Cell and Molecular \\ Biology, BV Patel Pharmaceutical \\ Education and Research Development \\ (PERD) Centre, Gujarat, India
}

\begin{abstract}
Drug discovery and drug delivery are two main aspects for treatment of a variety of disorders. However, the real bottleneck associated with systemic drug administration is the lack of target-specific affinity toward a pathological site, resulting in systemic toxicity and innumerable other side effects as well as higher dosage requirement for efficacy. An attractive strategy to increase the therapeutic index of a drug is to specifically deliver the therapeutic molecule in its active form, not only into target tissue, nor even to target cells, but more importantly, into the targeted organelle, ie, to its intracellular therapeutic active site. This would ensure improved efficacy and minimize toxicity. Cancer chemotherapy today faces the major challenge of delivering chemotherapeutic drugs exclusively to tumor cells, while sparing normal proliferating cells. Nanoparticles play a crucial role by acting as a vehicle for delivery of drugs to target sites inside tumor cells. In this review, we spotlight active and passive targeting, followed by discussion of the importance of targeting to specific cell organelles and the potential role of cell-penetrating peptides. Finally, the discussion will address the strategies for drug/DNA targeting to lysosomes, mitochondria, nuclei and Golgi/endoplasmic reticulum.
\end{abstract}

Keywords: intracellular drug delivery, cancer chemotherapy, therapeutic index, cell penetrating peptides

\section{Introduction}

Targeted drug delivery is essential for several diseases like cancer, which is characterized by groups of cells exhibiting properties of uncontrolled and undifferentiated growth, invasion, and sometimes metastasis, ie, spread of cancer to other tissues with the aid of connective tissues like blood and lymph. According to the American Cancer Society, globally, around 7.6 million deaths were due to cancer, and nearly 12.7 million cases of cancer were diagnosed in 2008. ${ }^{1,2}$ The most general cancer treatments are restricted to chemotherapy, radiation, and surgery. Frequent challenges encountered by existing cancer therapies include nonspecific systemic distribution of chemotherapeutic agents, inadequate drug concentrations reaching the tumor, and limited ability to monitor therapeutic responses. ${ }^{3}$ Nanoparticles are used for delivering drugs to the brain by infiltrating the blood-brain barrier. The advantage of using a nanocarrier system is that it can cross the blood-brain barrier while keeping the original characteristics of the therapeutic drug molecule intact. There are several drugs that have been successfully transported into the brain using nanoparticle carriers including hexapeptide dalargin, dipeptide kyotorphin, loperamide, tubocurarine, the N-methyld-aspartate receptor antagonist MRZ 2/576, doxorubicin, etc. Presently, nanoparticle iron chelators have been used for treatment of Alzheimer's disease and other neu-
Correspondence: Harish Padh Department of Cell and Molecular Biology, BV Patel Pharmaceutical Education and Research Development (PERD) Centre, Sarkhej-Gandhinagar Highway, Thaltej, Ahmedabad - 380 054, Gujarat, India Tel +9l 7927450449 Fax+91 7927450449 Email hpadh@yahoo.com 
rological disorders associated with trace metal imbalance. Further, polymeric nanoparticles coated with polyethylene glycol (PEG) are efficient drug carriers for delivery of active therapeutic molecules in prion disease. ${ }^{4}$ Consider the case of inflammatory diseases: the specific uptake of nanoparticles by immune-related cells in inflamed barriers offers selective drug targeting to inflamed tissues. Nanoparticle-based drug delivery uses several strategies for treatment of common inflammatory disorders like rheumatoid arthritis, multiple sclerosis, uveitis, or inflammatory bowel diseases. ${ }^{5}$ Several intestinal diseases like Crohn's disease have been treated via targeted drug delivery. This was achieved by localizing delivery of glucocorticosteroid budesonide to the ileum and ascending colon. ${ }^{6}$ Several aspects determine the effectiveness of a pharmaceutical drug. Of most concern is how well a drug molecule is able to reach its intended target. The primary goal is to enhance effectiveness of a chemotherapeutic drug by increasing toxicity to cancer cells, while decreasing toxicity to normal cells, which defines its therapeutic index. ${ }^{7}$ Thus the need for targeted drug delivery has been well accepted in modern drug therapy.

Two major goals in the development of therapeutic agents or imaging contrast formulations are greater targeting selectivity and better delivery efficacy. A rational approach to attain these goals is to conjugate therapeutic drugs to monoclonal antibodies or ligands that selectively bind to various receptors that are usually abundantly or exclusively expressed on the target cell surface. There are approximately six ligand-targeted therapeutic strategies being developed, which comprise chemotherapeutics, antisense RNAs, molecularly targeted agents, immunotoxins, and drug immunoconjugates. ${ }^{8}$ Although these conjugated agents have demonstrated promising efficacy compared with conventional chemotherapeutic drugs in preclinical and clinical trials, ${ }^{9}$ there are various limitations in efficiency and specificity of their delivery mechanisms.

By increasing the proportion of drug accumulation in target cells versus normal cells, researchers hope to minimize the potential side effects of therapy and thereby increase therapeutic effects. ${ }^{10}$ Diverse groups of scientists have taken this approach one step further by targeting to specific sites inside the target cells, where drugs may exert cell-killing activity. As of yet, most of the current nanoparticle formulations are not designed to deliver drugs/DNA to specific organelles inside the cell; pharmaceutical nanotechnology as applied to the level of cell organelles - the subcellular level - is an emerging field in drug delivery systems. ${ }^{11}$ However, several nanoparticles can be coated with organelle targeting moieties such as the nuclear localization signal (NLS), ${ }^{12}$ Tat peptide ${ }^{13}$ or mitochondrial targeting sequence (MTS) ${ }^{14}$ for achieving organelle targeted delivery. Intracellular fate of nanoparticles depends on their size and composition. For example, anionic polymeric particles of about $43 \mathrm{~nm}$ in diameter were reported to be internalized via clathrindependent endocytosis, following which they were directed to a degradative pathway. On the other hand, nanoparticles of about $24 \mathrm{~nm}$ diameter were taken up via a cholesterolindependent, clathrin-caveolin-independent pathway, not to a degradative pathway, in HeLa and human umbilical vein endothelial cell lines. ${ }^{15}$ Beyond the advances made over the last decade in using nanocarriers to increase tissue accumulation of drug molecules, improve drug efficacy, and reduce unwanted side effects, the successes in subcellular targeting of drugs has recently gained broader recognition. ${ }^{16}$

Intracellular drug delivery, or subcellular targeting, is beneficial for therapeutic action under various scenarios. First, the quantity of a therapeutic molecule required for the desired effect may be significantly reduced because of its specificity, eventually leading to a decrease in side effects. Second, and most importantly, intracellular drug delivery will overcome the most critical limitation of drug actions, ie, multidrug resistance, which has been a major hurdle in cancer chemotherapy. ${ }^{17}$

\section{Drug delivery strategies}

Macromolecular conjugation to low molecular weight drugs has prevented their passive diffusion into highly circulated tissue systems throughout the body, resulting in lower toxicity. The use of macromolecules for drug delivery provides a prime advantage: a mechanism by which the drug is internalized. The cell has an active internalization mechanism, whereby the membrane invaginates, forming a vesicle known as an endosome. ${ }^{18}$ Various targeting strategies are classified broadly as active or passive targeting; both strategies will be discussed below.

\section{Endocytosis-based drug delivery}

Of late, most of the drugs being targeted for various disorders like cancer adopt a mechanism of endocytosis. Endocytosis, as its name suggests, is the invagination of the cytoplasm to absorb molecules by engulfing them. ${ }^{19}$ Once the molecule is invaginated, it forms a vesicle called an endosome, which eventually fuses with a lysosome and converts to an endolysosome. ${ }^{19}$ Endocytosis can be further classified into phagocytosis, pinocytosis, and receptor mediated endocytosis (Figure 1). Phagocytosis, a process observed in specific 


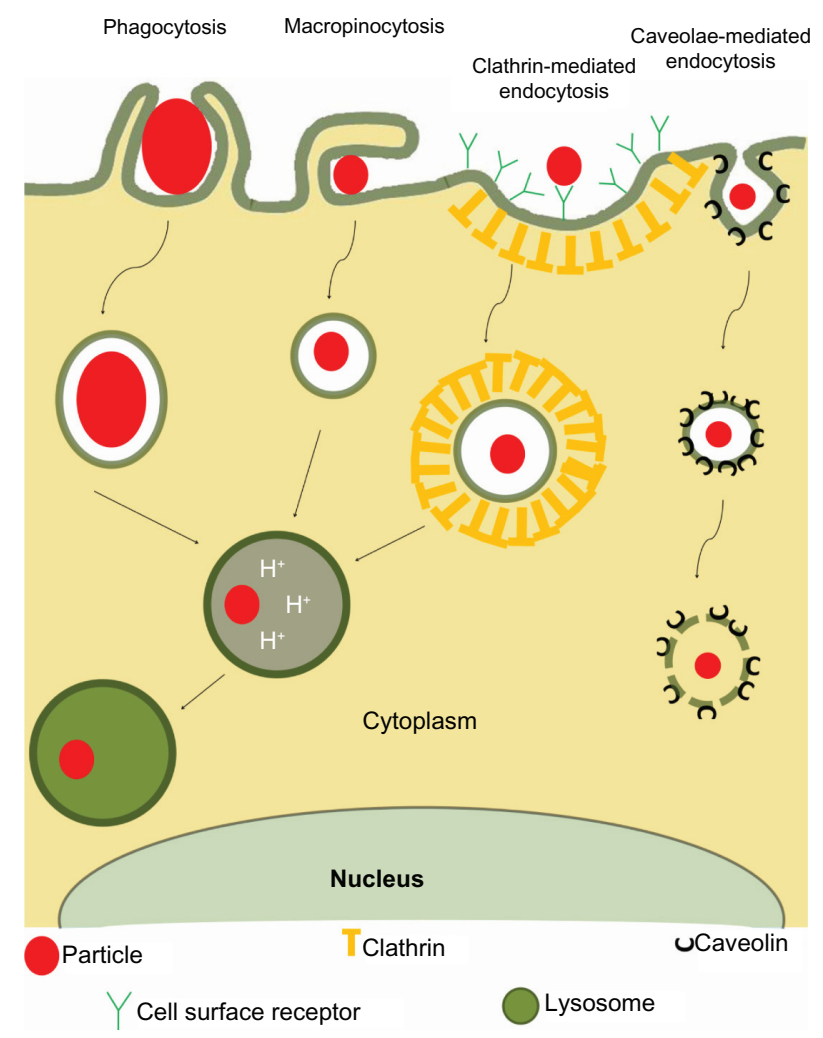

Figure I Four major types of endocytosis.

Notes: The figure depicts phagocytosis, which is the engulfment of large particles/ macro-organisms; macropinocytosis, which is the nonspecific uptake of particles/ solute; clathrin-mediated endocytosis, which forms the major part of receptor mediated endocytosis; and caveolae-mediated endocytosis, demonstrated by cells expressing caveolin protein. Except for caveolae-mediated endocytosis, all pathways result in fusion with the lysosome.

Abbreviation: $\mathrm{H}^{+}$, hydrogen ion.

cells (macrophages and neutrophils in vertebrates), is a phenomenon whereby cells take up large particles $(>0.5 \mu \mathrm{m})$ by actin-dependent mechanisms, which are usually independent of clathrin. ${ }^{20}$ Due to its specificity, phagocytosis may not be typically considered for designing nanoparticles for subcellular targeting applications. On the other hand, pinocytosis and receptor-mediated endocytosis are clathrin-dependent mechanisms for the uptake of macromolecules, viruses, and small particles. ${ }^{21}$ Pinocytosis is usually independent of actin-dependent mechanisms. Table 1 summarizes various endocytic uptake mechanisms.

Endocytosis is the major uptake mechanism of cells and any biological agents. These agents are entrapped in endosomes and are eventually degraded by specific enzymes in lysosomes. This results in limited delivery of therapeutic agents to the intracellular target site. Consequently, there are a few attempts being made to deliver drugs by the nonendocytic route, or by avoiding lysosomal fusion and facilitating endosomal escape $^{22}$ for ensuring cytosolic delivery of the therapeutics.

\section{Active and passive targeting}

Drug targeting strategies can be broadly classified into two categories: passive targeting and active targeting. Passive targeting refers to the accumulation of a drug or drug-carrier system at a specific site due to physicochemical or pharmacological factors. This class of targeting relies on the properties of tumor tissues as well as the particular disease pathology, which may preferentially aid accumulation of a drug in target tissues and hence decrease nonspecificity. Consider the case for cancer: there are differences in endothelial structures called fenestrations between normal vasculature and tumor associated vessels. ${ }^{8}$ Tumor vasculatures have wider fenestrations; a nanocarrier would preferentially accumulate to a larger extent in such tumor tissue fenestrations as compared to normal tissues. ${ }^{23}$ The blood vessels in tumor tissue are different from normal tissues as they show extensive angiogenesis, high vascular density, extensive vascular permeability, defective vascular architecture, and impaired lymph clearance from the interstitial spaces of tumor tissue, all of which facilitate retention of a drug. ${ }^{24}$ The intracellular space of the angiogenic tumor vasculature is estimated to have an average pore size of 100-600 nm, significantly larger than the spaces found in normal endothelial cells within the normal blood vessels, which are typically $<6 \mathrm{~nm}$ wide. ${ }^{25}$ This phenomenon is called the enhanced permeation and retention effect. ${ }^{26}$ Alternatively, active targeting may be mediated through targeting agents like antibodies, ligands, etc, which can deliver the nanocarrier intracellularly based on specific interactions of the targeting moiety with a cell surface antigen or receptor. This strategy involves specific alteration of a drug/drug carrier nanosystem with the active agent which has selective affinity for recognizing and interacting with a specific cell, tissue, or organ in the body. Coupling drug carrier nanosystems to ligands allows several drug molecules to be imported by means of receptor-ligand interaction. The targeting of a drug to specific cells has been explored utilizing the presence of different receptors, antigens/proteins on the plasma membrane of cells, and by employing the lipid components of cell membranes. ${ }^{27}$ Receptor-mediated endocytosis occurs in pitted membrane regions lined either by caveolin-1 or clathrin proteins (Table 1). The proteins involved in a number of distinct receptor-mediated endocytic pathways have been elucidated using biochemical agents along with fluorescence imaging and confocal microscopy. Reports have shown that drug-loaded nanoparticles, when conjugated to ligands or to monoclonal antibodies against specific receptors, resulted in increased uptake via the receptor-mediated endocytic route. Numerous receptors including those of 
Table I Types of endocytosis

\begin{tabular}{|c|c|c|c|c|c|}
\hline Endocytosis type & Vesicle size & Shown by & Mechanism of internalization & Intracellular fate & Ref \\
\hline Phagocytosis & $>0.5 \mu \mathrm{m}$ & $\begin{array}{l}\text { Neutrophils } \\
\text { Macrophages }\end{array}$ & $\begin{array}{l}\text { Receptor-induced rearrangement } \\
\text { in actin cytoskeleton leading to } \\
\text { internalization of particle }\end{array}$ & $\begin{array}{l}\text { Lysosomal fusion to form } \\
\text { phagolysosome, followed } \\
\text { by degradation }\end{array}$ & 21 \\
\hline Macropinocytosis & $0.5 \mu \mathrm{m}-5 \mu \mathrm{m}$ & $\begin{array}{l}\text { Epithelial cells } \\
\text { Neutrophils } \\
\text { Fibroblasts } \\
\text { Macrophages }\end{array}$ & $\begin{array}{l}\text { Growth factor triggers plasma } \\
\text { membrane ruffling, followed } \\
\text { by sealing of aperture to form } \\
\text { macropinosomes }\end{array}$ & $\begin{array}{l}\text { Leakage from } \\
\text { macropinosomes, released } \\
\text { into cytoplasm }\end{array}$ & 126,127 \\
\hline $\begin{array}{l}\text { Clathrin-mediated } \\
\text { endocytosis }\end{array}$ & $100 \mathrm{~nm}-150 \mathrm{~nm}$ & All cells & $\begin{array}{l}\text { Ligand binds to cell surface } \\
\text { receptor, which recruits clathrin } \\
\text { to cell membrane. Cluster of } \\
\text { clathrin invaginates forms a vesicle } \\
\text { which engulfs the particle }\end{array}$ & $\begin{array}{l}\text { Cargo fuses with lysosome. } \\
\text { Clathrin and receptors are } \\
\text { recycled back to plasma } \\
\text { membrane }\end{array}$ & $128-130$ \\
\hline $\begin{array}{l}\text { Caveolae-mediated } \\
\text { endocytosis }\end{array}$ & $50 \mathrm{~nm}-60 \mathrm{~nm}$ & $\begin{array}{l}\text { Caveolin-I } \\
\text { expressing cells } \\
\text { or muscle cells that } \\
\text { have caveolin-3 }\end{array}$ & $\begin{array}{l}\text { Caveosomes (via caveolin protein) } \\
\text { form on the membrane, which is } \\
\text { mediated by small hydrophobic } \\
\text { microdomains rich in cholesterol } \\
\text { and glycosphingolipids }\end{array}$ & $\begin{array}{l}\text { No pH drop in endosomes. } \\
\text { The vesicle is sorted to } \\
\text { smooth ER or Golgi body }\end{array}$ & $|3|$ \\
\hline $\begin{array}{l}\text { Clathrin and caveolin- } \\
\text { independent endocytosis }\end{array}$ & $60 \mathrm{~nm}$ & & $\begin{array}{l}\text { Tyrosine kinase and cholesterol- } \\
\text { dependent endocytic pathway }\end{array}$ & $\begin{array}{l}\text { It delivers cargo/virus via } \\
\text { nonendosomal, cytosolic } \\
\text { organelles to ER }\end{array}$ & 132 \\
\hline
\end{tabular}

Abbreviations: ER, endoplasmic reticulum; Ref, reference number.

asialoglycoprotein ${ }^{28}$ epidermal growth factor, ${ }^{29}$ folate, ${ }^{30}$ chemokine $^{31}$ and transferrin ${ }^{32}$ serve as high affinity binding sites and have been investigated for their use in targeting to different cell types.

\section{Subcellular delivery mechanisms}

Subcellular delivery involves delivering a drug in its active form to its target site of action inside the cell. Before we discuss the various strategies for subcellular delivery (Figure 2), it is important to understand why it is necessary to target subcellular organelles. A discussion addressing the necessity to target each organelle will be followed by an examination of the strategies to achieve such directed targeting. Figure 3 presents the organelles and the various diseases with which they are associated. We begin by discussing cell penetrating peptides as a mechanism to cross various biological membranes. The reason cell-penetrating peptides (CPPs) are discussed separately is because of their similar delivery mechanisms of crossing various biological membranes.

\section{Cell penetrating peptides}

During the past 20 years, there has been growing interest regarding a class of peptides, known as CPPs, also referred to as protein transduction domains (PTDs), which can traverse the biological membrane. ${ }^{33} \mathrm{CPP}$ s have gained much attention, not only because of their ability to cross cell membranes in an energy-independent, nontoxic manner, but because of their capacity to support efficient cellular internalization of linked therapeutic biomolecules. ${ }^{34} \mathrm{~A}$ few of the well-documented CPPs are HIV-1 Tat DNA binding domain $^{35}$ and HSV-1 VP22 protein $^{36}$ of viral origin, drosophila's antennapedia DNA binding domain, ${ }^{37}$ and various synthetic peptides like polyarginine..$^{38}$ In 2001 Futaki et al showed that polyarginine has similar translocation activity as that of Tat Peptide. ${ }^{38}$ CPPs and related peptides are used for several applications which include delivering imaging contrast agents and radionuclides to cells and tissues,${ }^{39}$ drug delivery ${ }^{40}$ and intracellular drug accumulation. ${ }^{41}$ In 1999 , Schwarze et al showed that $\beta$-galactosidase, when fused with Tat, resulted in efficient internalization of a biologically active fusion protein in all tissues in mice, including the brain. ${ }^{42}$ Whereas in 2004, Muratovska and Eccles demonstrated coupling of small interfering RNA (siRNA) to penetratin and transportan for efficient uptake in cells. ${ }^{43}$ Further, in 2007, Bian et al engineered a chimeric protein, GATA4:VP22, which was efficiently taken up by cardiac cells in vivo for controlling stress. ${ }^{44}$

Mechanism of uptake of CPPs is still unclear. Descriptions of the internalization process range from energy-independent cell penetration of the cell membrane to endocytosis-mediated uptake. ${ }^{45}$ In 2003, it was shown that Tat fusion protein was internalized by a temperature-dependent endocytic process via cell membrane lipid rafts followed by caveolae-mediated endocytosis. ${ }^{46}$ However, it has also been revealed that Tatfusion proteins of above $30,000 \mathrm{Da}$ as well as Tat CPPs with a molecular weight of 1000-5000 Da were internalized by 
Cytoskeleton specific immunoliposome delivery-mediated by hypoxia induced lesions in plasma membrane.

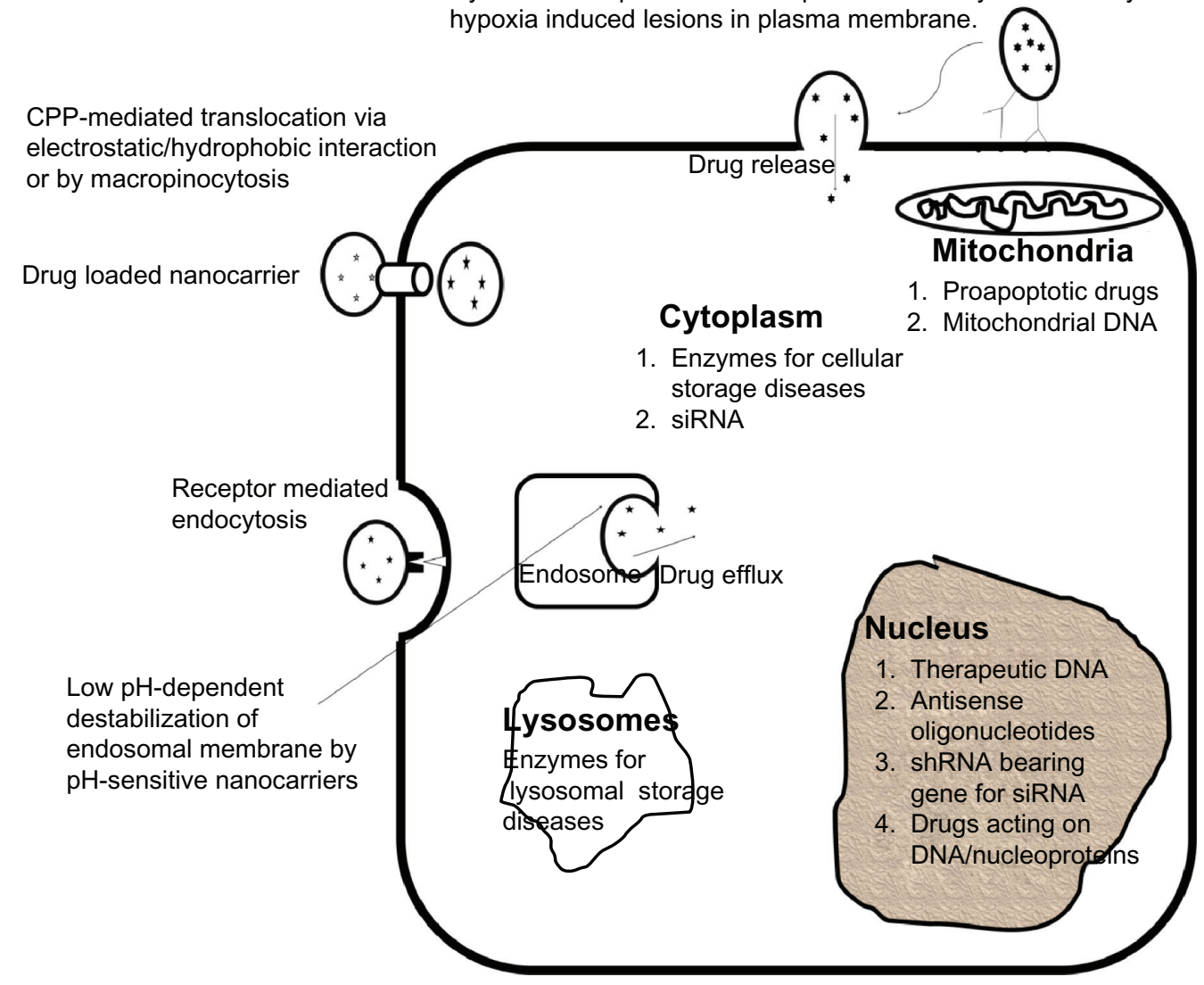

Figure 2 Intracellular drug delivery by various strategies to cytoplasm, nucleus, mitochondria, or lysosome and the targeting moieties to these organelles. Abbreviations: CPP, cell-penetrating peptide; siRNA, small interfering RNA; shRNA, small hairpin RNA; RNA, ribonucleic acid.

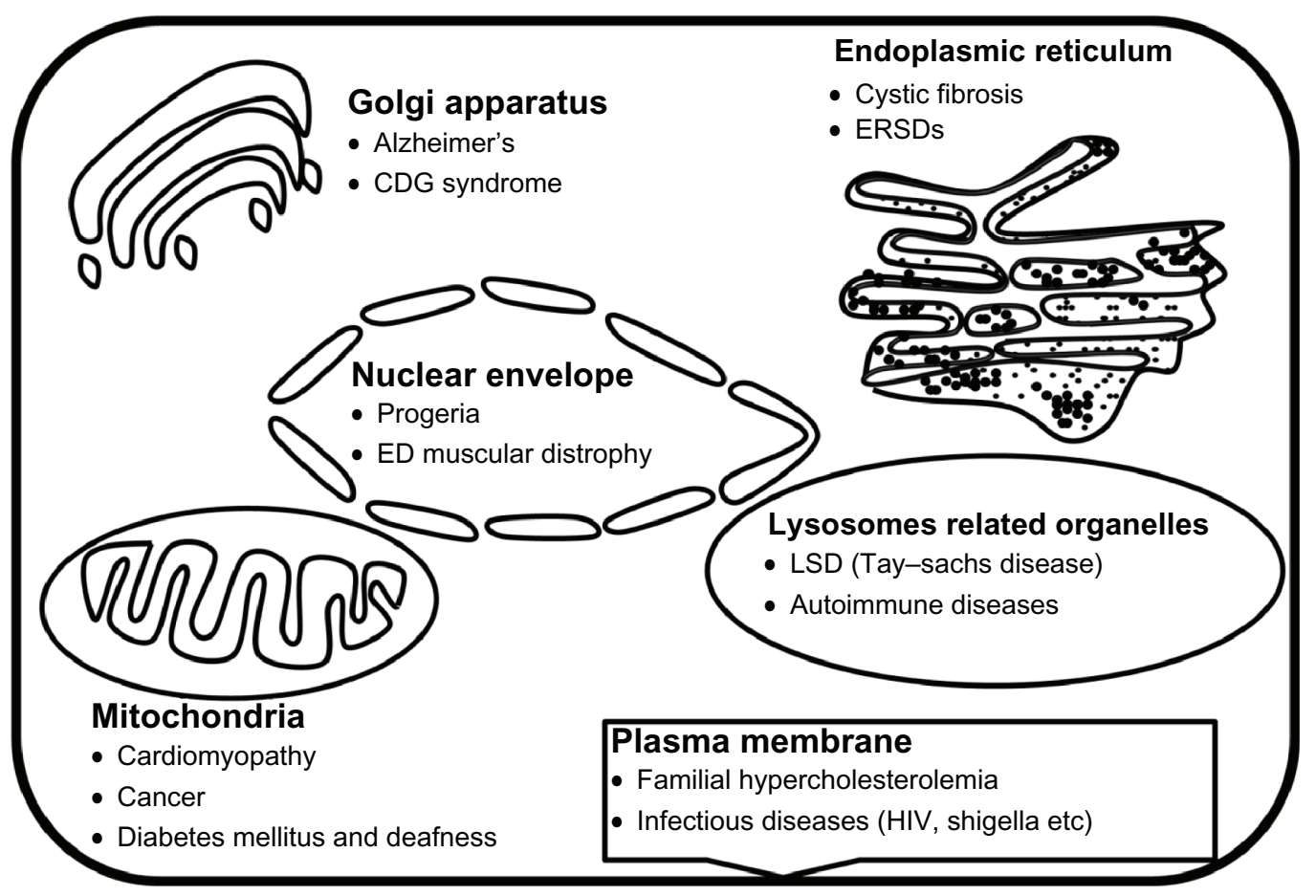

Figure 3 Diseases associated with specific cell-organelles.

Abbreviations: CDG, congenital disorders of glycosylation; ED, Emery-Dreifuss; ERSDs, endoplasmic reticulum storage diseases; LSD, lysosomal storage disease. 
macropinocytosis, a form of fluid phase endocytosis shown by all cells. ${ }^{47}$ Further, the effect of cargo on uptake mechanism was analyzed, and it was found that the mechanism of uptake depended on the size of cargo fused to Tat. A major fraction of the Tat-protein ended up in cytosolic vesicles, whereas Tat-peptides were distributed throughout the cell and were found to accumulate in the nucleolus. ${ }^{48}$ Additionally, direct penetration of CPP-cargo into cells depends on peptide concentration; if the concentration is above a critical threshold, internalization occurs via a nonendocytic pathway. ${ }^{49}$ Antennapedia DNA binding domain peptide differs from Tat and arginine-rich nona-arginine peptides in that it needs a partial blockade of the endocytic uptake pathway in order to be taken up by a nonendocytic route. ${ }^{50}$

CPPs have been demonstrated to show various toxic effects. They can be separated into two groups: arginine-rich peptides and amphipathic peptides. ${ }^{51}$ Amphipathic peptides can cause cell membrane leakage, which has been demonstrated by leakage of lactate dehydrogenase; leakage was very high in the case of amphipathic peptides and minimal for arginine-rich peptides, Tat and penetratin. ${ }^{52}$ When comparing three of the most common CPPs for membrane destabilization studies, two of which are highly cationic (ie, penetratin and Tat) and one which is amphipathic (TP10), fluorescein labeling on penetratin showed no difference when it is not attached, whereas Tat showed mild toxicity, and TP10 showed very high toxicity. Tat, when coupled to fluorescein, was not efficiently taken up by cells as compared to penetratin and TP10, whereas when coupled to protein, Tat translocation increased dramatically. Also, it has been shown that attachment of a particular cargo depends on uptake of the CPPcargo conjugate, thus using $\mathrm{CPP}$-fluorescein as a marker for uptake may not be feasible. ${ }^{53}$ Similarly, toxicity also depends on the cargo attached, ie, when double stranded DNA or protein were attached to CPPs, they decreased long-term toxicity of CPPs, as opposed to when fluorescein was attached to Tat, it increased the CPP's toxicity. ${ }^{53}$

\section{Nuclear delivery Why target the nucleus?}

The nucleus is the control center of the eukaryotic cell. The sequestering of genetic material within the nucleus of the eukaryotic cell provides the nucleus with a powerful mechanism for the regulation of gene expression and other cellular processes through selective translocation of proteins between the nucleus and cytoplasm. There are various drugs which act on DNA to prevent its replication and to decrease or inhibit transcription of a variety of important genes.
However, a therapeutic molecule, even if delivered inside the target cell, often fails to reach its subcellular target. For instance, only $0.1 \%$ of free plasmids from cytosol were able to translocate into the nucleus by crossing the nuclear membrane. ${ }^{54}$ There are various drugs which show similar results. Additionally, proliferating cells causing disease (such as in tumors) acquire genetic changes which may make them resistant to a particular drug, resulting in the production of new daughter cells that are also drug-resistant. Thus, there is a need for nanoparticle drug delivery systems that may directly and effectively deliver drugs or plasmids into the nucleus in order to circumvent the effect of adverse drug reactions.

The nuclear genome of humans comprises two copies each of 3.2 billion base pairs, with only $2 \%$ of that coding for 30,000 diverse proteins; with the rest of the genetic material being considered "junk" DNA. ${ }^{55-57}$ Mutations in these 30,000 genes, in the promoter/enhancer regions of these genes or in their splice sites, may lead to various kinds of disorders such as cancer, neurodegenerative diseases, heart dysfunction, brain disorders, etc. Huntington's disease, a neurodegenerative disorder, is the result of increased expression of the polyglutamine regions in huntingtin, a cytoplasmic protein, which eventually increases intranuclear inclusions. In 1999, Peters et al showed that when a mutant fragment of huntingtin was targeted using NLS, a $111 \%$ increase in cell loss was observed as compared to untargeted. ${ }^{58}$ Conversely, when a nuclear export signal was attached, cell loss was decreased by $57 \% .^{58}$ Thus, nuclear localization of mutant huntingtin is important for cell toxicity.

\section{Nuclear targeting}

The boundary between the nucleus and cytoplasm is a double membrane called the nuclear envelope, which is perforated with nuclear pore complex (NPC) structures through which nucleocytoplasmic transfer occurs. ${ }^{59}$ All passive and active transport across the nuclear envelope is through NPC, which has a central channel of only $9 \mathrm{~nm}$ and allows for the passive transport of molecules measuring less than $50 \mathrm{kDa}{ }^{60}$ Macromolecules larger than $50 \mathrm{kDa}$ require assistance from NLS and NPC. NLS-mediated transport involves energydependent recognition of NLS by the NLS receptor, which subsequently docks the cargo at the NPC. This is followed by an energy-dependent translocation via NPC and release of cargo into the nucleus. ${ }^{61}$

Various DNA viruses deliver their genetic material into the nucleus thus asserting their toxicity, as delivering their genetic material into the nucleus results in production of further viral particles. The study of viral delivery mechanisms 
has aided in the development of viral-mediated gene delivery strategies. The most commonly studied virus for this purpose is the adenovirus. Adenovirus type 2 and type 5 enter epithelial cells via endocytosis and enter the cytosol in an integrin-dependent manner. They are then translocated to a microtubule organizing complex and hence are translocated to the nucleus via microtubules. ${ }^{62}$ It was observed that the blocking of nuclear export factor, CRM1 (chromosome region maintenance 1), prevented detachment of the adenovirus from microtubules, and therefore prevented the virus from attaching to the nuclear membrane. ${ }^{62}$ On the other hand, Simian vacuolating virus 40 is first delivered to endocytic compartments that are coated with caveolin-1 protein, which travel to the endoplasmic reticulum (ER), and finally to the nucleus. ${ }^{63}$ The virus possibly employs a retrograde route to ER, which allows it to reside in the Golgi apparatus for a significant length of time. ${ }^{63}$ There are several advantages of using viral-mediated nuclear delivery, which facilitates high translocation efficiency, but owing to the presence of viral components, there is considerable toxicity associated with them, thereby limiting their use for drug delivery.

Small peptides from viruses that show nuclear localization, such as KKKRKV peptide from SV40 large T antigen, are used for nuclear delivery. Proteins bearing such NLS are recognized by the importin- $\alpha$ subunit of heterodimeric complexes in the cytoplasm. The importin- $\alpha$-protein-importin- $\beta$ trimeric complex is later translocated through NPC into the nucleoplasm, which requires guanosine triphosphatase Ran (GTPase-Ran). ${ }^{59}$ Binding of nuclear GTP-Ran to importin- $\beta$ dissociates the importin-NLS complex, leaving cargo protein and importin- $\alpha$ in the nucleoplasm. ${ }^{59}$ Cationic lipids complexed with DNA, called lipoplex, and cationic polymers complexed with DNA, called polyplex, are being used for DNA delivery into the nucleus. ${ }^{64}$ Lipoplexes were used in clinical trials for the treatment of melanoma. ${ }^{65}$

Most of the naturally occurring NLS are bipartite with a spacer of about ten to twelve amino acids between two NLS sequences. One of the best characterized NLS is nucleoplasmin, ${ }^{66}$ which has a minimal sequence of KRPAAT KKAGQAKKKKL. This NLS has been extensively used for coupling cargos like protein, peptide, DNA, and oligonucleotide and has been shown to effectively traverse the nuclear membrane. NLS not only consist of a basic amino acid domain, but they also contain an $\alpha$-helix destabilizing amino acid, proline or glycine residue upstream or downstream of the basic amino acids cluster, along with an additional cluster of acidic residues upstream or downstream of or within a spacer. Serine residues located in or around the cationic cluster are usually essential for transport and have been implicated as phosphorylation sites. Last but not the least, hydrophobic amino acids like tryptophan or tyrosine are excluded from NLS or from spacer that is present in bipartite NLS. ${ }^{66}$ Liposomes made from a small percentage of cationic lipid form complexes with DNA, and when modified with Tat peptide, they have shown fast and efficient translocation into the cell cytoplasm and subsequently into the nucleus. ${ }^{67}$

\section{Mitochondrial delivery Why target the mitochondria?}

The primary role of mitochondria in eukaryotes is to provide adenosine triphosphate (ATP) to the cell by the process of oxidative phosphorylation, and hence it is known as the powerhouse of the cell. In 1926, Otto Warnberg ${ }^{68}$ first found that cancerous cells produced most of their ATP via the glycolytic pathway even under aerobic conditions. Thus he proposed that this "aerobic glycolysis," shown specifically by cancerous cells, may cause impairment in mitochondrial function. ${ }^{69}$ Mitochondria play a key role in apoptosis as well, therefore mutations in apoptotic-related genes like p53, PTEN, Bcl-2 and their homologues may be involved in the development of chemoresistance in most human cancers. ${ }^{70}$ Mitochondria also modulate the intracellular calcium concentration ${ }^{71}$ and carry out oxidative phosphorylations via the mitochondrial respiratory chain, which is a major process for the removal of reactive oxygen species. ${ }^{72}$ Consequently, the malfunctioning of mitochondria is found in several adult-onset diseases such as obesity, diabetes, cardiomyopathy, Parkinson's, infertility, migraine, blindness, deafness, kidney and liver diseases, and stroke. It has been suggested that somatic mutations in the mitochondrial genome are involved in aging, age-related neurodegenerative disease, neuromuscular diseases, as well as in cancer. Hence, they are being considered as a prime target in pharmacological interventions. ${ }^{73}$ Mitochondrial damage could be prevented by decreasing oxidative damage and calcium overload. Strategies for treating mitochondrial gene mutations include mitochondrial targeted drugs which could nullify the effect of mutant genes. ${ }^{73}$ Heteroplasmy is a situation in which pathogenic mitochondrial DNA coexists among wild type mitochondrial DNA within the same cells and tissues of an individual. The expression of biochemical and clinical defects arise only when a critical level of heteroplasmy has been exceeded. ${ }^{74}$ Various molecules that could be targeted to the mitochondria include RNA or DNA (eg, antisense oligonucleotides, ribozymes, plasmid DNA expressing mitochondrial genes, etc), which may provide a basis for treatment of mitochondrial DNA diseases. Additional treatment 
strategies may include delivery of antioxidants to protect mitochondria from oxidative stress or proapoptotic drugs, which could trigger apoptosis in tumor cells. Lastly but not of least importance, proteins and peptides may be delivered for treatment of a wide range of mitochondrial disorders. ${ }^{75}$

\section{Mitochondrial targeting}

A huge range of clinically approved drugs, such as paclitaxel, ${ }^{76}$ VP-16 (etoposide), ${ }^{77}$ betulinic acid, ${ }^{78}$ lonidamine, CD-437 (a synthetic retinoids), and ceramide, ${ }^{70}$ act directly on mitochondria to trigger apoptosis; however, to date there is no specific nanocarrier for targeting the mitochondria in mammalian cells. Nevertheless, there have been some attempts made to deliver cargos to mitochondria (Figure 4). The first attempts to achieve mitochondrial drug delivery were based on membrane potential. This delivery was achieved using a small molecule, vitamin $\mathrm{E}$, which acts as an antioxidant against reactive oxygen species generated in mitochondria. Covalent coupling of vitamin $\mathrm{E}$ to a triphenylphosphonium cation was driven by a large membrane potential $(-150$ to $-180 \mathrm{mV})$ across the mitochondrial inner membrane. ${ }^{79}$ Hence, triphenylphosphiniummodified vitamin $\mathrm{E}$ crossed the lipid bilayer and accumulated in mitochondrial matrix more efficiently, compared to native vitamin E. ${ }^{79}$ The second strategy used for mitochondrial targeting was peptide based, using MTS. Most mitochondrial proteins are nuclear-encoded, ie, they are translated in the cytosol and then imported into the mitochondria. Most of these proteins have N-terminal MTS, which are nonspecific and

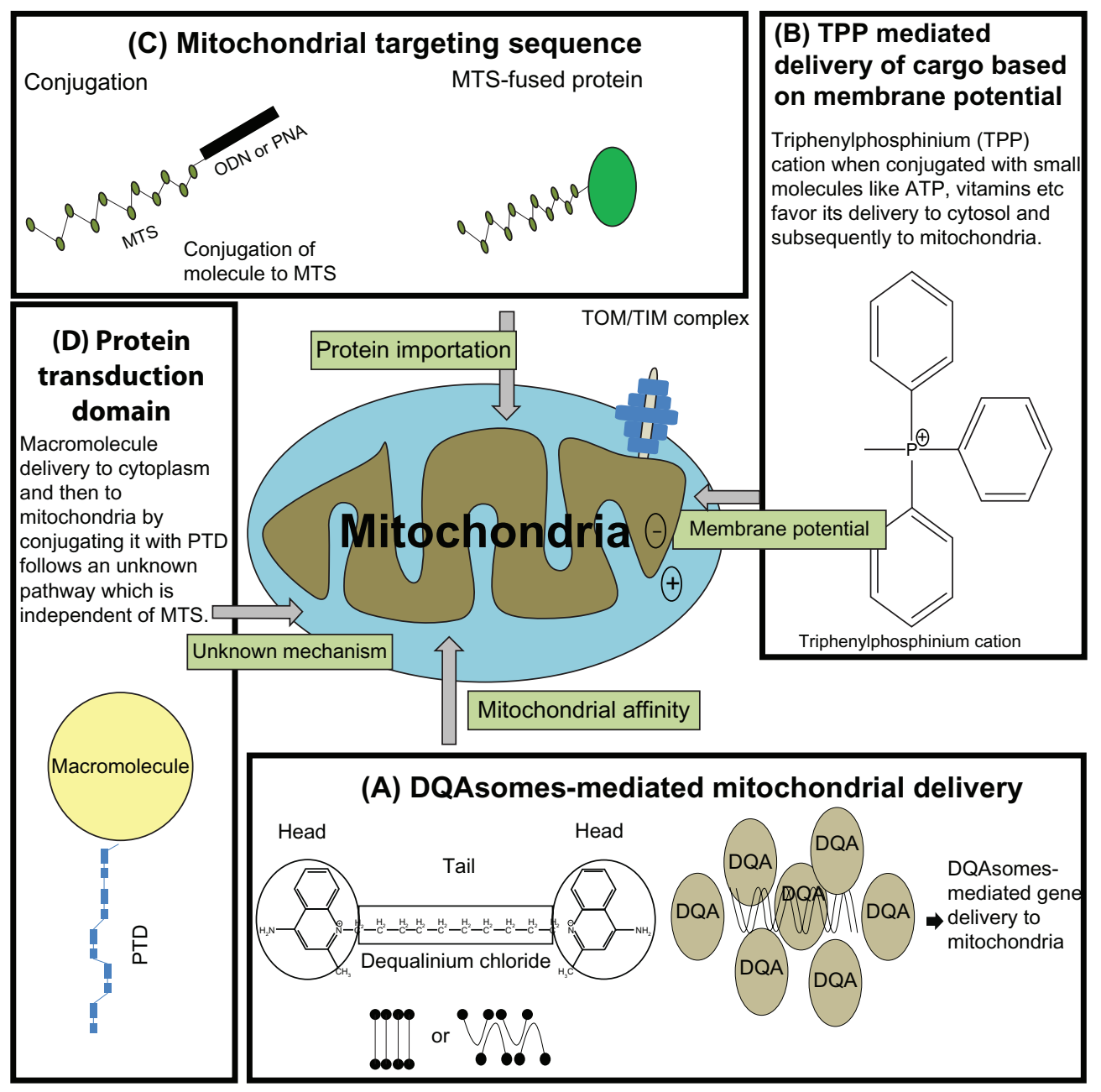

Figure 4 Current approaches being used for successful mitochondrial specific delivery.

Notes: (A) Mitochondrial affinity bearing DQAsomes formed by single chain bolaamphiphiles. Right side shows DQAsomes and DNA forming complexes, DQAplexes, that transport DNA specifically to mitochondria. (B) TPP-mediated delivery of cargo is based on membrane potential created by high negative potential of the mitochondrial inner membrane, thus attachment of TPP to small molecules delivers them initially to the cytoplasm and subsequently to mitochondria. (C) Mitochondrial targeting sequences (MTS) when covalently cross-linked to large molecules like peptide nucleic acids (PNA) or oligodeoxynucleotides (ODN) can be delivered to mitochondria. When the MTS gene is fused with a gene of interest, MTS-fused protein is expressed in the cytosol and delivers the protein to mitochondria. (D) Macromolecules conjugated to the protein transduction domain (PTD) have been found to accumulate in mitochondria due to an unknown mechanism. PTD is known to bypass the classical protein import pathway and accumulate in cytosol. Abbreviations: ATP, adenosine triphosphate; TOM/TIM, translocse of the outermembrane/translocase of the innermembrane; DQA, dequalinium; DQAsomes, dequalinium based liposome-like vesicles. 
part of the mature protein, but the physiochemical properties of these sequences are more or less similar. ${ }^{80}$ Approximately $70 \%$ of MTS are rich in basic and hydroxylated amino acids, which have the capacity to form an amphipathic $\alpha$-helix. ${ }^{80}$ The remaining $30 \%$ of these proteins lack such sequences, but paradoxically, they contain targeting information as mature proteins. ${ }^{81}$ There are various studies reporting gene therapy with restriction enzymes being targeted to the mitochondria using MTS. For example the restriction endonuclease Sma1, which selectively digests mutant DNA (having mutation at 8993 T G), was targeted to mitochondria by fusion to MTS. Consequently it was observed that Sma1 fused MTS showed specific elimination of mutant mitochondrial DNA. ${ }^{82}$ The third approach of mitochondrial targeting was carried out by using a molecule/nanocarrier that displayed affinity for mitochondria. Dequalinium chloride is a typical mitochondriotropic delocalized cation that is shown to selectively accumulate in the mitochondria of carcinoma cells. ${ }^{83}$ Dequalinium-based liposome-like vesicles (DQAsomes) were proposed by Weissig et al in 1998 to be the first mitochondrial-specific colloidal drug and DNA delivery system. ${ }^{84}$ There is a distinct self-assembly behavior of dicationic quinolinium derivatives, which are mitochondriotropic cationic resembling bola-form electrolytes, ie, they have symmetrical head groups separated by a tail. ${ }^{84}$ Upon sonication such bola-like amphiphiles form an aqueous suspension of cationic vesicles called bolasomes, or DQAsomes, with diameters between $70 \mathrm{~nm}-700 \mathrm{~nm}$. It has been hypothesized that due to the positive charge and the mitochondriotropic properties of DQAsomes, they may be able to bind or entrap various drugs and DNA and transport them to mitochondrion due to the mitochondrial membrane potential. ${ }^{84}$ In 2001, Weissig et al demonstrated that DNA complexed with DQA formed DQAplexes, ${ }^{85}$ and were shown to release the DNA upon contact with the mitochondrial surface. Further, when mitochondrial leader sequence-conjugated plasmid was situated in DQAsomes, oligonucleotides were shown to be colocalized with mitochondria in mammalian cells. ${ }^{86}$ Paclitaxel, an antimicrotubule chemotherapeutic drug, at a relevant concentration, triggered apoptosis in mitochondria by inducing release of cytochrome $\mathrm{c}$ in a permeability transition pore-dependent manner. When mixed with paclitaxel, DQA formed paclitaxel encapsulated DQAsomes that triggered apoptosis in vitro. ${ }^{87}$

\section{Lysosomal/endosomal delivery}

Targeting to the lysosome/endosome involves two contradictory aspects. One aspect is to directly target therapeutics to the lysosome/endosome through receptor-mediated endocytosis, and the other aspect involves strategies which will ensure escape from the lysosome/endosome in order to prevent degradation so that therapeutics may remain intact and available in the cytosol for their further action.

\section{Why target the lysosome/endosome?}

Discovered by Christian de Duve in $1955,{ }^{88}$ lysosomes are single membranous, subcellular organelles involved in macromolecule turnover. They have an acidic $\mathrm{pH}$ within their lumen and approximately 60 hydrolases capable of degrading various biological macromolecules. Cargo reaches the lysosome through various pathways: exogenously via phagosomes or endosomes, and endogenously via autophagy. ${ }^{89}$ Autophagy is a critical process whereby dysfunctional organelles are subjected to degradation in lysosomes to provide cellular nutrition in the case of starvation..$^{90}$ To date, approximately 50 monogenic diseases are primarily associated with lysosomes, of which the majority fall within the category of lysosomal storage diseases. Any disruption of lysosomal function can lead to an accumulation of undegraded substrates in endosomes and lysosomes, eventually compromising cellular function. ${ }^{89}$ Tay-Sachs disease, Gaucher's disease, Fabry disease, Niemann-Pick disease, Hurler syndrome, Pompe disease, etc, are a few examples arising due to such disruption..$^{91}$ In addition to lysosomal storage diseases, lysosomes have also been linked to Alzheimer's, autoimmune diseases, and resistance to autoimmune diseases. ${ }^{89}$ Particular enzyme deficiency in lysosomes may also lead to downstream deactivation of proteins. For example, endothelin-converting enzyme-1 (ECE-1) is involved in the degradation of substance P (SP) in early endosomes of epithelial cells and neurons, which disrupts endosomal SPneurokinin ${ }_{1}$ receptor- $\beta$-arrestin-Src-mitogen activated protein kinases signalosome. SP degradation attenuates extracellular signal related kinase-2 (ERK2) activation in the cytosol and nucleus preventing activation of Nur77 death receptors. ECE-1 inhibition causes endosomal retention of the SP neurokinin 1 receptor and $\beta$-arrestins resulting in markedly sustained ERK2 activation in the cytosol and nucleus, which eventually activates Nur77 death receptors, leading to cell death. ${ }^{92}$ Thus, ECE-1 attenuates ERK2 mediated SP signaling in the nucleus to prevent cell death. Hence ECE-1 is a major target for disease involving inflammation and pain. ${ }^{92}$

\section{Lysosomal/endosomal targeting}

Endosomes are not only involved in degradation, but they are also involved in recycling of molecules and receptors on the cell surface. Being acidic organelles, lysosomes are involved 
in the degradation of extracellular molecules and autophagy (turnover of intracellular cytosolic molecules and organelles). ${ }^{93}$ Primarily, for targeting a molecule to the endosome/lysosomes, receptors expressed on the cell surface like folate, transferrin, vascular endothelial growth factor, and low density lipoproteins are used. In lysosomal storage disorders, targeting of degradative enzymes to lysosomes may result in reversal of the disease conditions. ${ }^{91}$ Lysosomes contain soluble and transmembrane proteins, which are targeted to lysosomes after their synthesis in the cytoplasm. The main targeting signal for proteins destined for the lysosomes is mannose-6-phosphate, which is recognized by the Golgi complex, followed by transport to the endosomal/lysosomal system. ${ }^{93}$ One lysosomal storage disease, Gaucher's disease, is caused by a deficiency of glucocerebrosidase ( $\beta$-glucosidase), the enzyme present in lysosomes and involved in the final step of sphingolipid degradation. The outcome is accumulation of glucocerebroside in macrophages, resulting in a tremendous enlargement of the spleen and liver, disabling bone involvement, and sometimes pulmonary incapacity. ${ }^{94}$ The therapeutic strategy used was treatment with glucocerebrosidase derived from the human placenta. Within a year significant improvement was seen in treated patients. Later, this placental enzyme was replaced by a recombinant enzyme derived from the chinese hamster ovary, with modification to expose mannose residues on oligosaccharides. ${ }^{94}$ Exposing the mannose residue targets the infused enzyme to mannose receptors of fixed tissue macrophages, the cells affected by storage - receptor-mediated endocytosis delivers the enzyme to lysosomes where the accumulated substrate is stored. ${ }^{44}$ There are basically two classes of motifs for targeting to lysosomes: tyrosine-based and dileucine-based sorting signals. The tyrosine-based motif has consensus sequence $\mathrm{YXX} \phi$ where $\mathrm{X}$ is any amino acid and $\phi$ is amino acid with bulky hydrophobic side chain. ${ }^{95}$ The dileucine-based motif has either [DE]XXXL[LI] or a DXXLL pattern, which targets cargo to lysosomes, where square brackets indicate alternatives. ${ }^{95}$ Finally, insulin-like growth factor II- $\beta$-glucuronidase was shown to be delivered with the aid of the insulin-like growth factor II/mannose 6 -phosphate receptor, and use of Tat- $\beta$-glucuronidase was used for uptake by absorptive endocytosis followed by delivery into the lysosomes. ${ }^{96}$

\section{Strategies for endosomal escape}

Efficient escape of drug molecules to the cytosol before their destruction in endolysosomes is a major challenge for intracellular drug delivery. Various strategies are being employed to address this issue such as using fusogenic peptides, $\mathrm{pH}$ sensitive polymers, $\mathrm{pH}$ sensitive core shell nanoparticles, and $\mathrm{pH}$ sensitive liposomes..$^{22}$ These carriers exploit low $\mathrm{pH}$ conditions of endosomes for their mode of action. For example, fusogenic peptides, which assume a random coil at $\mathrm{pH}$ 7.0, show conformational change at a lower $\mathrm{pH}$ and either fuse with the membrane, lyse it, or create pores, hence releasing all its content into the cytosol. ${ }^{97}$ Consider the case of epidermal growth factor receptor (EGFR) and kirsten ras (KRAS): EGFR is important in the carcinogenesis of colorectal cancer, hence antiEGFR therapy may be a potential treatment option..$^{98}$ The $K R A S$ gene encodes a protein that transmits signal from EGFR downstream to activate important cell functions, in particular proliferation and survival. Mutation of KRAS leads to uncontrolled signaling and uncontrolled proliferation and hence makes tumors resistant to anti-EGFR therapies. ${ }^{98,99}$ Oliveira et al demonstrated that when siRNA of $E G F R$ and $\mathrm{K}$-ras oncogene was given along with influenzaderived fusogenic peptide dilNF-7, a strong enhancement of gene silencing activity was achieved as opposed to absence of the peptide, proving endosomal escape was a limiting factor for siRNA silencing efficiency. ${ }^{97}$

Various cationic polymers like polyethyleneimine (PEI) show endosomal escape by two mechanisms. The first method is by the interaction of PEI with the endosomal membrane, making it porous and thus facilitating leakage of various cargos into the cytosol. The other mechanism is by PEI buffering action within the endosomal compartment, which eventually leads to osmotic swelling of the vesicle, the subsequent burst of the endosome, and the release of internal components into the cytosol along with the therapeutic molecule. This effect is known as the proton sponge effect. ${ }^{100}$

Another strategy for endosomal escape is by employing cationic lipids or cationic polymers. Positively charged liposomes/polymers bind to negatively charged phosphates of DNA, forming a complex. Generally, positive charges are in excess so that the overall charge of the complex becomes positive, aiding interaction with the negatively charged cell surface. ${ }^{22}$ For facilitating endosomal escape, lipids such as dioleoyl phosphatidylethanolamine are being used for synthesis of liposomes instead of distearoyl phosphatidylethanolamine. ${ }^{101}$ This facilitates destabilization of liposomal membranes under low $\mathrm{pH}$ conditions, which is followed by fusion with the endosomal membrane and release of liposomal contents into cytoplasm. ${ }^{101} \mathrm{~A}$ different phenomenon is observed when PEI is being used as carrier for DNA as mentioned previously; polyplexes (PEI complexed with DNA) lead to swelling and subsequent bursting of vesicles. ${ }^{102}$ 
Further, there are several chemical compounds which are used to facilitate endosomal escape. ${ }^{103}$

\section{Golgi/endoplasmic reticulum delivery Why target the Golgi/endoplasmic reticulum?}

Camillo Golgi, over a century ago, first described the Golgi apparatus (Golgi body) as an "internal reticular apparatus". ${ }^{104}$ It is the central organelle of the cell secretory pathway and interacts with ER. It carries out posttranslational modification of newly synthesized proteins by employing various enzymes for phosphorylation, acylation, glycosylation, methylation, and sulfation. ${ }^{105}$ These modifications may be signal sequences, for example, if mannose-6-phosphate is added, then the protein will be destined for the lysosome. ${ }^{105}$ The Golgi apparatus is also involved in the synthesis of proteoglycans and carbohydrate structures, which include the production of glycosaminoglycans, polysaccharides (pectin and hemicellulose), etc. ${ }^{105}$ Certain pathological changes, pharmacological agents, and overexpression of Golgi-associated proteins cause profound alterations in the Golgi apparatus. Alterations in the neuronal Golgi apparatus gives rise to a variety of neurodegenerative disorders which include Alzheimer's, Parkinson's, Niemann-Pick disease, and others. ${ }^{106}$ The other most familiar Golgi-linked diseases are a group of 15 congenital disorders of glycosylation. They are caused by mutations in genes that encode glycosylation enzymes or glycosylation-linked transport proteins; such mutations are usually lethal by the age of 2 years. ${ }^{106}$ Symptoms include mental retardation, seizures, and liver disease. ${ }^{106}$ Further, the Golgi apparatus as well as the ER have been postulated as future targets for anticancer therapy. ${ }^{107}$ Drugs directed against the Golgi have been shown to be effective in both androgen-dependent and androgen-independent prostate cancer. Abnormal glycosylation has been reported in prostate cancer. ${ }^{108}$ The Thomsen-Friedenreich antigen is expressed on the surface of prostate cancer cells and may be involved in the adhesion of cancer cells to endothelial cells or in immune attack evasion. ${ }^{109}$

The ER is a network of folded membrane-enclosed tubules and sacs (cisternae) that extend from the nuclear membrane throughout the cytoplasm. ${ }^{60}$ Its primary function is to facilitate the folding of secretory and membrane proteins. Additionally, it is involved in calcium storage, calcium signaling, and has been shown to play a role in apoptosis regulation against disturbances in calcium homeostasis, ischemia, hypoxia, exposure to free radicals, oxidative stress, elevated protein synthesis, and gene mutations. ${ }^{110}$ All of these instabilities lead to ER dysfunction and are collectively termed ER stress. For example, glucose-regulated protein 78 (GRP78), which is a chaperone protein, plays a crucial role as indicated by the observation that overexpression of GRP78 protected cells from death associated with ER stress, whereas downregulation of GRP78 increased the sensitivity of cells to ER stress. ${ }^{111}$ ER storage diseases are a group of geneticallybased disorders in which mutant proteins are produced by the ER. They may be caused by the absence of a protein, the presence of a mutant protein, or the misfolding of a protein. Examples of ER storage diseases are familial hypoparathyroidism, coagulation factor X deficiency, Crigler-Najjar syndrome type II, familial central diabetes insipidus, and chronic pancreatitis. ${ }^{112}$ Deficiency of thyroglobulin, which is synthesized in the thyrocytes and secreted into the follicular lumen, is the cause of congenital goiter, a common inborn error leading to congenital hypothyroidism. The occurrence of this condition is approximately one in 40,000 live births, and it may lead to hypothyroid growth retardation, abnormal central nervous system function, and local compression of neck tissues due to an enlarged thyroid mass. ${ }^{113}$ The ER has also been associated with cancer, and is a target for new upcoming cancer drugs. ${ }^{110}$

\section{Golgi/endoplasmic reticulum targeting}

Both the ER and Golgi apparatus are part of the secretory pathway that transports proteins to the plasma membrane via vesicular trafficking. As mentioned by Wlodkowic et al, ${ }^{107}$ the ER-Golgi network is a future target for anticancer therapy, and there are various strategies for targeting molecules to this network. A notable example is the effort to target rapamycin, the central regulator of mammalian cell growth and proliferation in response to environmental and nutritional conditions. The mammalian target of rapamycin (mTOR) signaling pathway is regulated via growth factors, amino acids, ATP, and $\mathrm{O}_{2}$ levels. ${ }^{114}$ mTOR signaling regulates cell-cycle progression, translation initiation, transcriptional stress responses, protein stability, and cell survival. ${ }^{114}$ The mTOR pathway lies both upstream and downstream of the phosphoinositide 3-kinase pathway. In some cancer cells, mTOR activation results, via negative feedback, in the inhibition of phosphoinositide 3-kinase signaling. Hence, inhibition of mTOR (eg, by rapamycin), the associated loss of negative feedback results in increase in activity of phosphoinositide 3-kinase and its effector Akt/PKB (Protein Kinase B), thereby decreasing the antiproliferative effect of mTOR inhibition and hence playing a crucial role 
in cancer. ${ }^{115}$ A major proportion of mTOR is localized in the ER and Golgi. ${ }^{116}$ It has been shown that using four sequences, which include two internal mTOR sequences ie, Huntingtin, elongation factor 3 (EF3), protein phosphatase 2A (PP2 $\underline{\mathrm{A}}$ ), and the yeast kinase (TOR1) (HEAT) repeats, HEAT18 and HEAT19, and two intervening interunit spacers (IUS), IUS17 and IUS18, green fluorescent protein can be targeted to the Golgi. Deletion of IUS17 targeted it to the ER instead of to the Golgi. ${ }^{117}$ Let us consider the case of cancer: misfolded proteins are exported from the ER to the cytosol by ER-associated protein degradation. ${ }^{118} \mathrm{~A}$ defect in this process causes the accumulation of misfolded proteins in ER leading to ER stress. Proper functionality of the ubiquitin proteosome system is very important for cancer cells as well as their role in degradation of various cell cycle factors. ${ }^{119}$ Hence a drug such as bortezomib, which is a proteosome inhibitor has cytotoxic effects in various cancer cell lines, and is used for clinical tests for multiple myeloma and mantle cell lymphoma. ${ }^{120}$ Bortezomib may induce cytotoxicity in cancer cells by induction of the BH3 (Bcl-2 homology 3)-only proapoptotic protein, NOXA. Wang et al have shown that Eeyarestatin I has cytotoxic effects preferentially for cancerous cells. ${ }^{120}$ In addition, they claim that Eeyarestatin I and bortezomib have similar characteristics by inducing cell death via BH3-only protein NOXA. ${ }^{120}$

\section{Conclusion}

Drug therapy is based on the paradigm that the drug will selectively show its pharmacological activity to render the patient free from negative side effects and decrease the symptoms and/or cause of the disease. Most of the drugs which show good pharmacological activity against a particular pathogen are toxic to humans when given at higher doses. Thus, it is of prime importance that a drug is delivered directly to its site of action within the target cell. Understanding the microenvironment of the diseased site will make it possible to design drug delivery systems that can specifically target, not only tissue and cells of interest, but the cell organelle. Hence, designing a nanoparticle-based drug delivery system would have several goals, including delivering increased drug concentration at the diseased site (active/passive targeting), limiting minimal drug concentration to the rest of the tissues, improving pharmacokinetic and pharmacodynamics profiles, improving solubility and stability, achieving improved internalization of intracellular delivery, and finally, attaining biocompatibility and biodegradability. ${ }^{8}$ A common method to protect a nanocarrier from the reticuloendothelial system is via PEGylation. The size of the nanocarrier is an important factor in the design of the drug delivery vector, which not only determines the mode of internalization, but the intracellular fate as well. To facilitate the release of drugs from inside the endosome/lysosome, several $\mathrm{pH}$ sensitive lipids like dioleoyl phosphatidylethanolamine or $\mathrm{pH}$-sensitive polymers are used for the design of nanocarriers. Therefore, knowledge of microenvironment in the diseased site, along with therapeutic requirements is essential for designing a drug delivery system.

There are numerous clinically approved nanocarriers that target tumors passively, for example, Doxil (liposomal Doxorubicin), ${ }^{121}$ Abraxane (Albumin-paclitaxel), ${ }^{122}$ etc, and several of those that are actively targeted are still in clinical trials, such as oxaliplatin in transferrin-PEG-liposome, ${ }^{123}$ paclitaxel loaded galactosamine-conjugated micelles, etc. ${ }^{124}$ Conversely, no drug delivery system that can target a specific organelle inside target cells has reached clinical trials.

Thus, in this review, we have compiled some of the ongoing research activities in the field of subcellular targeting, citing several relevant examples. However, little is currently known about subcellular targeting using nanoparticles. There are several unanswered questions: do they remain intact upon cell entry and subsequent disposition? What is the true influence of size on intracellular disposition of nanoparticles? ${ }^{125}$ Based on advantages and challenges of various delivery systems, sensible selection of materials and products is essential. Finally, a better understanding of molecular basics of various diseases will help in increasing the number and quality of intracellular therapeutic vectors.

\section{Acknowledgment}

The authors would like to sincerely acknowledge the Department of Biotechnology, Government of India, and the Council of Scientific and Industrial Research, Government of India for financial support.

\section{Disclosure}

The authors report no conflicts of interest in this work.

\section{References}

1. Jemal A, Bray F, Center MM, Ferlay J, Ward E, Forman D. Global cancer statistics. CA Cancer J Clin. 2011;61(2):69-90.

2. Ferlay J, Shin HR, Bray F, Forman D, Mathers C, Parkin DM. Estimates of worldwide burden of cancer in 2008: GLOBOCAN 2008. Int J Cancer. 2010;127(12):2893-2917.

3. Drabu S, Khatri S, Babu S, Verma D. Nanotechnology: An introduction to future drug delivery system. J Chem Pharm Res. 2010;2(1): 171-179.

4. Chakraborty C, Sarkar B, Hsu CH, Wen ZH, Lin CS, Shieh PC. Future prospects of nanoparticles on brain targeted drug delivery. J Neurooncol. 2009;93(2):285-286.

5. Ulbrich W, Lamprecht A. Targeted drug-delivery approaches by nanoparticulate carriers in the therapy of inflammatory diseases. $J R$ Soc Interface. 2010;7(Suppl 1):S55-S66. 
6. Wikberg M, Ulmius J, Ragnarsson G. Review article: Targeted drug delivery in treatment of intestinal diseases. Aliment Pharmacol Ther. 1997;11(Suppl 3):109-115.

7. Muller PY, Milton MN. The determination and interpretation of the therapeutic index in drug development. Nat Rev Drug Discov. 2012;11(10):751-761.

8. Danhier F, Feron O, Préat V. To exploit the tumor microenvironment: passive and active tumor targeting of nanocarriers for anti-cancer drug delivery. J Control Release. 2010;148(2):135-146.

9. Sapra P, Tyagi P, Allen TM. Ligand-targeted liposomes for cancer treatment. Curr Drug Deliv. 2005;2(4):369-381.

10. Wang X, Yang L, Chen Z, Shin DM. Application of nanotechnology in cancer therapy and imaging. CA Cancer J Clin. 2008;58(2):97-110.

11. D'Souza G, Weissig V. An introduction to subcellular nanomedicine: current trends and future developments. In: Weissig W, D’Souza GGM, editors. Organelle-Specific Pharmaceutical Nanotechnology. Hoboken, NJ: John Wiley \& Sons, Inc; 2010:1-13.

12. Kang B, Mackey MA, El-Sayed MA. Nuclear targeting of gold nanoparticles in cancer cells induces DNA damage, causing cytokinesis arrest and apoptosis. J Am Chem Soc. 2010;132(5):1517-1519.

13. de la Fuente JM, Berry CC. Tat peptide as an efficient molecule to translocate gold nanoparticles into the cell nucleus. Bioconjug Chem. 2005;16(5):1176-1180.

14. Flierl A, Jackson C, Cottrell B, Murdock D, Seibel P, Wallace DC. Targeted delivery of DNA to the mitochondrial compartment via import sequence-conjugated peptide nucleic acid. Mol Ther. 2003;7(4): $550-557$.

15. Lai S, Hida K, Man ST, et al. Privileged delivery of polymer nanoparticles to the perinuclear region of live cells via a non-clathrin, nondegradative pathway. Biomaterials. 2007;28(18):2876-2884.

16. Rajendran L, Knölker HJ, Simons K. Subcellular targeting strategies for drug design and delivery. Nat Rev Drug Discov. 2010;9(1):29-42.

17. Cheng SM, Boddapati SV, D’Souza G, Weissig V. DQAsomes as mitochondria-targeted nanocarriers for anti-cancer drugs. Nanotechnology for Cancer Therapy. Boca Raton, FL:CRC/Taylor and Francis; 2006: 787-802.

18. Bareford L, Swaan PW. Endocytic mechanisms for targeted drug delivery. Adv Drug Deliv Rev. 2007;59(8):748-758.

19. Neekhra N, Padh H. An insight into molecular mechanism of endocytosis. Indian J Biochem Biophys. 2004;41(2-3):69-80.

20. García-García E, Rosales C. Signal transduction during Fc receptormediated phagocytosis. J Leukoc Biol. 2002;72(6):1092-1108.

21. Aderem A, Underhill DM. Mechanisms of phagocytosis in macrophages. Annu Rev Immunol. 1999;17:593-623.

22. Dominska M, Dykxhoorn DM. Breaking down the barriers: siRNA delivery and endosome escape. J Cell Sci. 2010;123(Pt 8):1183-1189.

23. Greish K. Enhanced permeability and retention (EPR) effect for anticancer nanomedicine drug targeting. Methods Mol Biol. 2010;624:25-37.

24. Maeda H, Fang J, Inutsuka T, Kitamoto Y. Vascular permeability enhancement in solid tumor: various factors, mechanisms involved and its implications. Int Immunopharmacol. 2003;3(3):319-328.

25. Wu HC, Chang DK. Peptide-mediated liposomal drug delivery system targeting tumor blood vessels in anticancer therapy. J Oncol. 2010; 2010:723798.

26. Jagadale R, Sakhrani N, Padh H. Drug delivery and drug targeting using therapeutic nanoparticles. Nanotechnology: Present Status and Future Prospects in Developing Countries. New Delhi:Daya Publishing House; 2011:110-132.

27. Vasir J, Reddy M, Labhasetwar V. Nanosystems in drug targeting: opportunities and challenges. Curr Nanosci. 2005;1(1):47-64.

28. Wilson A, Zhou W, Champion HC, et al. Targeted delivery of oligodeoxynucleotides to mouse lung endothelial cells in vitro and in vivo. Mol Ther. 2005;12(3):510-518.

29. Mamot C, Drummond DC, Greiser U, et al. Epidermal growth factor receptor (EGFR)-targeted immunoliposomes mediate specific and efficient drug delivery to EGFR- and EGFRvIII-overexpressing tumor cells. Cancer Res. 2003;63(12):3154-3161.
30. Parker N, Turk MJ, Westrick E, Lewis JD, Low PS, Leamon CP. Folate receptor expression in carcinomas and normal tissues determined by a quantitative radioligand binding assay. Anal Biochem. 2005;338(2): 284-293.

31. Biragyn A, Ruffini PA, Coscia M, et al. Chemokine receptor-mediated delivery directs self-tumor antigen efficiently into the class II processing pathway in vitro and induces protective immunity in vivo. Blood. 2004;104(7):1961-1969.

32. Li H, Qian ZM. Transferrin/transferrin receptor-mediated drug delivery. Med Res Rev. 2002;22(3):225-250.

33. Gautam A, Chaudhary K, Kumar R, Sharma A, Kapoor P, Tyagi A, Open source drug discovery consortium, Raghava GPS. In silico approaches for designing highly effective cell penetrating peptides. Journal of Translational Medicine. 2013;11:74.

34. Lindgren M, Hällbrink M, Prochiantz A, Langel U. Cell-penetrating peptides. Trends Pharmacol Sci. 2000;21(3):99-103.

35. Li Y, Rosal RV, Brandt-Rauf PW, Fine RL. Correlation between hydrophobic properties and efficiency of carrier-mediated membrane transduction and apoptosis of a p53 C-terminal peptide. Biochem Biophys Res Commun. 2002;298(3):439-449.

36. Roeder GE, Parish JL, Stern PL, Gaston K. Herpes simplex virus VP22human papillomavirus E2 fusion proteins produced in mammalian or bacterial cells enter mammalian cells and induce apoptotic cell death. Biotechnol Appl Biochem. 2004;40(Pt 2):157-165.

37. Joliot A, Pernelle C, Deagostini-Bazin H, Prochiantz A. Antennapedia homeobox peptide regulates neural morphogenesis. Proc Natl Acad Sci U S A. 1991;88(5):1864-1868.

38. Futaki S, Suzuki T, Ohashi W, et al. Arginine-rich peptides. An abundant source of membrane-permeable peptides having potential as carriers for intracellular protein delivery. J Biol Chem. 2001;276(8):5836-5840.

39. Kersemans V, Cornelissen B. Targeting the tumour: cell penetrating peptides for molecular imaging and radiotherapy. Pharmaceuticals. 2010;3(3):600-620.

40. Vivès E, Schmidt J, Pèlegrin A. Cell-penetrating and cell-targeting peptides in drug delivery. Biochim Biophys Acta. 2008;1786(2): $126-138$.

41. Juliano RL. Intracellular delivery of oligonucleotide conjugates and dendrimer complexes. Ann NY Acad Sci. 2006;1082:18-26.

42. Schwarze SR, Ho A, Vocero-Akbani A, Dowdy SF. In vivo protein transduction: delivery of a biologically active protein into the mouse. Science. 1999;285(5433):1569-1572.

43. Muratovska A, Eccles MR. Conjugate for efficient delivery of short interfering RNA (siRNA) into mammalian cells. FEBS Lett. 2004;558(1-3):63-68.

44. Bian J, Popovic ZB, Benejam C, Kiedrowski M, Rodriguez LL, Penn MS. Effect of cell-based intercellular delivery of transcription factor GATA4 on ischemic cardiomyopathy. Circ Res. 2007;100(11):1626-1633.

45. Maniti O, Blanchard E, Trugnan G, Lamazière A, Ayala-Sanmartin J. Metabolic energy-independent mechanism of internalization for the cell penetrating peptide penetratin. Int J Biochem Cell Biol. 2012;44: 869-875.

46. Fittipaldi A, Ferrari A, Zoppé M, et al. Cell membrane lipid rafts mediate caveolar endocytosis of HIV-1 Tat fusion proteins. J Biol Chem. 2003; 278(36):34141-34149.

47. Kaplan IM, Wadia JS, Dowdy SF. Cationic TAT peptide transduction domain enters cells by macropinocytosis. J Control Release. 2005; 102(1):247-253.

48. Tünnemann G, Martin RM, Haupt S, Patsch C, Edenhofer F, Cardoso MC. Cargo-dependent mode of uptake and bioavailability of TAT-containing proteins and peptides in living cells. FASEB J. 2006; 20(11):1775-1784.

49. Madani F, Lindberg S, Langel Ü, Futaki S, Gräslund A. Mechanisms of Cellular Uptake of Cell-Penetrating Peptides. Journal of Biophysics. 2011:1-10.

50. Duchardt F, Fotin-Mleczek M, Schwarz H, Fischer R, Brock R. A comprehensive model for the cellular uptake of cationic cell-penetrating peptides. Traffic. 2007;8(7):848-866. 
51. Mo RH, Zaro JL, Shen W-C. Comparison of cationic and amphipathic cell penetrating peptides for siRNA delivery and efficacy. Mol Pharm. 2012;9:299-309.

52. Saar K, Lindgren M, Hansen M, et al. Cell-penetrating peptides: a comparative membrane toxicity study. Anal Biochem. 2005; 345(1):55-65.

53. El-Andaloussi S, Järver P, Johansson HJ, Langel U. Cargo-dependent cytotoxicity and delivery efficacy of cell-penetrating peptides: a comparative study. Biochem J. 2007;407(2):285-292.

54. Pollard H, Remy JS, Loussouarn G, Demolombe S, Behr JP, Escande D. Polyethylenimine but not cationic lipids promotes transgene delivery to the nucleus in mammalian cells. J Biol Chem. 1998;273(13): 7507-7511.

55. Lander ES, Linton LM, Birren B, et al. Initial sequencing and analysis of the human genome. Nature. 2001;409(6822):860-921.

56. Venter JC, Adams MD, Myers EW, et al. The sequence of the human genome. Science. 2001;291(5507):1304-1351.

57. Waterston RH, Lindblad-Toh K, Birney E, et al. Initial sequencing and comparative analysis of the mouse genome. Nature. 2002;420(6915): 520-562.

58. Peters MF, Nucifora FC Jr, Kushi J, et al. Nuclear targeting of mutant Huntingtin increases toxicity. Mol Cell Neurosci. 1999;14(2): 121-128.

59. Yasuhara N, Takeda E, Inoue H, Kotera I, Yoneda Y. Importin alpha/ beta-mediated nuclear protein import is regulated in a cell cycledependent manner. Exp Cell Res. 2004;297(1):285-293.

60. Macara IG. Transport into and out of the nucleus. Microbiol Mol Biol Rev. 2001;65(4):570-594.

61. Chan CK, Jans DA. Using nuclear targeting signals to enhance non-viral gene transfer. Immunol Cell Biol. 2002;80(2):119-130.

62. Strunze S, Trotman LC, Boucke K, Greber UF. Nuclear targeting of adenovirus type 2 requires CRM1-mediated nuclear export. $\mathrm{Mol} \mathrm{Biol}$ Cell. 2005;16(6):2999-3009.

63. Nabi IR, Le PU. Caveolae/raft-dependent endocytosis. J Cell Biol. 2003;161(4):673-677.

64. Li S, Huang L. Nonviral gene therapy: promises and challenges. Gene ther. 2000;7(1):31-34.

65. Nabel GJ, Nabel EG, Yang ZY, et al. Direct gene transfer with DNAliposome complexes in melanoma: expression, biologic activity, and lack of toxicity in humans. Proc Natl Acad Sci U S A. 1993;90(23): 11307-11311.

66. Robbins J, Dilworth SM, Laskey RA, Dingwall C. Two interdependent basic domains in nucleoplasmin nuclear targeting sequence: identification of a class of bipartite nuclear targeting sequence. Cell. 1991;64(3):615-623.

67. Torchilin VP, Levchenko TS, Rammohan R, Volodina N, PapahadjopoulosSternberg B, D’Souza GG. Cell transfection in vitro and in vivo with nontoxic TAT peptide-liposome-DNA complexes. Proc Natl Acad Sci US A. 2003;100(4):1972-1977.

68. Kim J, Dang CV. Cancer's Molecular Sweet Tooth and the Warburg Effect. Cancer Research. 2006;66:8927-8930.

69. Warburg O. On the origin of cancer cells. Science. 1956;123(3191): 309-314.

70. Costantini P, Jacotot E, Decaudin D, Kroemer G. Mitochondrion as a novel target of anticancer chemotherapy. J Natl Cancer Inst. 2000; 92(13):1042-1053.

71. Duchen MR. Roles of mitochondria in health and disease. Diabetes. 2004;53(Suppl 1):S96-S102.

72. Czarna M, Jarmuszkiewicz W. [Role of mitochondria in reactive oxygen species generation and removal; relevance to signaling and programmed cell death.] Postepy Biochem . 2006;52(2):145-156. Polish [with English abstract].

73. Murphy MP, Smith RA. Drug delivery to mitochondria: the key to mitochondrial medicine. Adv Drug Deliv Rev. 2000;41(2):235-250.

74. Taylor RW, Wardell TM, Smith PM, et al. An antigenomic strategy for treating heteroplasmic mtDNA disorders. Adv Drug Deliv Rev. 2001; 49(1-2):121-125.
75. Weissig V, Cheng SM, D’Souza GG. Mitochondrial pharmaceutics. Mitochondrion. 2004;3(4):229-244.

76. Kidd JF, Pilkington MF, Schell MJ, et al. Paclitaxel affects cytosolic calcium signals by opening the mitochondrial permeability transition pore. J Biol Chem. 2002;277(8):6504-6510.

77. Robertson JD, Gogvadze V, Zhivotovsky B, Orrenius S. Distinct pathways for stimulation of cytochrome c release by etoposide. J Biol Chem. 2000;275(42):32438-32443.

78. André N, Braguer D, Brasseur G, et al. Paclitaxel induces release of cytochrome $\mathrm{c}$ from mitochondria isolated from human neuroblastoma cells. Cancer Res. 2000;60(19):5349-5353.

79. Smith RA, Porteous CM, Coulter CV, Murphy MP. Selective targeting of an antioxidant to mitochondria. Eur J Biochem. 1999;263(3): 709-716.

80. Abe Y, Shodai T, Muto T, et al. Structural basis of presequence recognition by the mitochondrial protein import receptor Tom20. Cell. 2000;100(5):551-560.

81. Stojanovski D, Johnston AJ, Streimann I, Hoogenraad NJ, Ryan MT. Import of nuclear-encoded proteins into mitochondria. Exp Physiol. 2003;88(1):57-64.

82. Tanaka M, Borgeld HJ, Zhang J, et al. Gene therapy for mitochondrial disease by delivering restriction endonuclease SmaI into mitochondria. J Biomed Sci. 2002;9(6 Pt 1):534-541.

83. Weiss MJ, Wong JR, Ha CS, et al. Dequalinium, a topical antimicrobial agent, displays anticarcinoma activity based on selective mitochondrial accumulation. Proc Natl Acad Sci USA. 1987;84(15): 5444-5448.

84. Weissig V, Lasch J, Erdos G, Meyer HW, Rowe TC, Hughes J. DQAsomes: a novel potential drug and gene delivery system made from Dequalinium. Pharm Res. 1998;15(2):334-337.

85. Weissig V, D'Souza GG, Torchilin VP. DQAsome/DNA complexes release DNA upon contact with isolated mouse liver mitochondria. J Control Release. 2001;75(3):401-408.

86. D'Souza GG, Boddapati SV, Weissig V. Mitochondrial leader sequence - plasmid DNA conjugates delivered into mammalian cells by DQAsomes co-localize with mitochondria. Mitochondrion. 2005;5(5):352-358.

87. D'Souza GG, Cheng SM, Boddapati SV, Horobin RW, Weissig V. Nanocarrier-assisted sub-cellular targeting to the site of mitochondria improves the pro-apoptotic activity of paclitaxel. J Drug Target. 2008;16(7):578-585.

88. De Duve C, Pressman BC, Gianetto R, Wattiaux R, Appelmans F. Tissue fractionation studies. 6. Intracellular distribution patterns of enzymes in rat-liver tissue. Biochem. J. 1955;60(4):604-617.

89. Lübke T, Lobel P, Sleat DE. Proteomics of the lysosome. Biochim Biophys Acta. 2009;1793(4):625-635.

90. Bagshaw RD, Mahuran DJ, Callahan JW. A proteomic analysis of lysosomal integral membrane proteins reveals the diverse composition of the organelle. Mol Cell Proteomics. 2005;4(2): 133-143.

91. Parkinson-Lawrence EJ, Shandala T, Prodoehl M, Plew R, Borlace GN, Brooks DA. Lysosomal storage disease: revealing lysosomal function and physiology. Physiology (Bethesda). 2010;25(2): $102-115$.

92. Cottrell GS, Padilla BE, Amadesi S, et al. Endosomal endothelinconverting enzyme-1: a regulator of beta-arrestin-dependent ERK signaling. J Biol Chem. 2009;284(33):22411-22425.

93. Ni X, Canuel M, Morales CR. The sorting and trafficking of lysosomal proteins. Histol Histopathol. 2006;21(8):899-913.

94. Sly WS, Vogler C. Brain-directed gene therapy for lysosomal storage disease: going well beyond the blood-brain barrier. Proc Natl Acad Sci US A. 2002;99(9):5760-5762.

95. Behnke J, Eskelinen EL, Saftig P, Schröder B. Two dileucine motifs mediate late endosomal/lysosomal targeting of transmembrane protein 192 (TMEM192) and a C-terminal cysteine residue is responsible for disulfide bond formation in TMEM192 homodimers. Biochem J. 2011;434(2):219-231. 
96. Grubb JH, Vogler C, Sly WS. New strategies for enzyme replacement therapy for lysosomal storage diseases. Rejuvenation Res. 2010;13(2-3):229-236.

97. Oliveira S, van Rooy I, Kranenburg O, Storm G, Schiffelers RM. Fusogenic peptides enhance endosomal escape improving siRNAinduced silencing of oncogenes. Int J Pharm. 2007;331(2):211-214.

98. Ballestrero A, Garuti A, Cirmena G, et al. Patient-tailored treatments with anti-EGFR monoclonal antibodies in advanced colorectal cancer: KRAS and beyond. Curr Cancer Drug Targets. 2012;12(4): 316-328.

99. Chen J, Huang XF, Katsifis A. Activation of signal pathways and the resistance to anti-EGFR treatment in colorectal cancer. J Cell Biochem. 2010;111(5):1082-1086.

100. Neu M, Fischer D, Kissel T. Recent advances in rational gene transfer vector design based on poly(ethylene imine) and its derivatives. J Gene Med. 2005;7(8):992-1009.

101. Khalil IA, Kogure K, Akita H, Harashima H. Uptake pathways and subsequent intracellular trafficking in nonviral gene delivery. Pharmacol Rev. 2006;58(1):32-45.

102. Boussif O, Lezoualc'h F, Zanta MA, et al. A versatile vector for gene and oligonucleotide transfer into cells in culture and in vivo: polyethylenimine. Proc Natl Acad Sci U SA. 1995;92(16):7297-7301.

103. Varkouhi AK, Scholte M, Storm G, Haisma HJ. Endosomal escape pathways for delivery of biologicals. J Control Release. 2011;151(3): 220-228.

104. Mazzarello P, Bentivoglio M. The centenarian Golgi apparatus. Nature. 1998;392(6676):543-544.

105. Alberts B, Johnson A, Lewis J, Raff M, Roberts K, Walter P. Vesicular Traffic in the Secretory and Endocytic Pathways Molecular Biology of the Cell, 4th ed. New York, NY: Garland; 2002:1065-1126.

106. Aridor M, Hannan LA. Traffic jam: a compendium of human diseases that affect intracellular transport processes. Traffic. 2000;1(11): 836-851.

107. Wlodkowic D, Skommer J, McGuinness D, Hillier C, Darzynkiewicz Z. ER-Golgi network - a future target for anti-cancer therapy. Leuk Res. 2009;33(11):1440-1447.

108. Migita T, Inoue S. Implications of the Golgi apparatus in prostate cancer. Int J Biochem Cell Biol. 2012;44(11):1872-1876.

109. Glinsky VV, Glinsky GV, Rittenhouse-Olson K, et al. The role of Thomsen-Friedenreich antigen in adhesion of human breast and prostate cancer cells to the endothelium. Cancer Res. 2001;61(12): 4851-4857.

110. Boelens J, Lust S, Offner F, Bracke ME, Vanhoecke BW. Review. The endoplasmic reticulum: a target for new anticancer drugs. In Vivo. 2007;21(2):215-226.

111. Paschen W, Frandsen A. Endoplasmic reticulum dysfunction a common denominator for cell injury in acute and degenerative diseases of the brain? J Neurochem. 2001;79(4):719-725.

112. Rutishauser J, Spiess M. Endoplasmic reticulum storage diseases Swiss Med Wkly. 2002;132(17-18):211-222.

113. Medeiros-Neto G, Kim PS, Yoo SE, et al. Congenital hypothyroid goiter with deficient thyroglobulin. Identification of an endoplasmic reticulum storage disease with induction of molecular chaperones. J Clin Invest. 1996;98(12):2838-2844.

114. Pópulo H, Lopes JM, Soares P. The mTOR signalling pathway in human cancer. Int J Mol Sci. 2012;13(12):1886-1918.
115. Hanahan D, Weinberg RA. Hallmarks of cancer: the next generation. Cell. 2011;144(5):646-674.

116. Drenan RM, Liu X, Bertram PG, Zheng XF. FKBP12-rapamycinassociated protein or mammalian target of rapamycin (FRAP/mTOR) localization in the endoplasmic reticulum and the Golgi apparatus. J Biol Chem. 2004;279(1):772-778.

117. Liu X, Zheng XF. Endoplasmic reticulum and Golgi localization sequences for mammalian target of rapamycin. Mol Biol Cell. 2007;18(3):1073-1082.

118. McCracken AA, Brodsky JL. Evolving questions and paradigm shifts in endoplasmic-reticulum-associated degradation (ERAD). Bio Essays. 2003;25:868-877.

119. Ye Y. Diverse functions with a common regulator: ubiquitin takes command of an AAA ATPase. J Struct Biol. 2006;156:29-40.

120. Wang Q, Mora-Jensen H, Weniger MA, et al. ERAD inhibitors integrate ER stress with an epigenetic mechanism to activate $\mathrm{BH} 3$-only protein NOXA in cancer cells. Proc Natl Acad Sci USA. 2009;106(7): 2200-2205.

121. Skubitz KM. Phase II trial of pegylated-liposomal doxorubicin (Doxil) in mesothelioma. Cancer Invest. 2002;20(5-6):693-699.

122. Fader AN, Rose PG. Abraxane for the treatment of gynecologic cancer patients with severe hypersensitivity reactions to paclitaxel. Int J Gynecol Cancer. 2009;19(7):1281-1283.

123. Suzuki R, Takizawa T, Kuwata Y, et al. Effective anti-tumor activity of oxaliplatin encapsulated in transferrin-PEG-liposome. Int J Pharm. 2008;346(1-2):143-150.

124. Wang YC, Liu XQ, Sun TM, Xiong MH, Wang J. Functionalized micelles from block copolymer of polyphosphoester and poly(epsiloncaprolactone) for receptor-mediated drug delivery. J Control Release 2008;128(1):32-40.

125. Solomon M, D’Souza GGM. Approaches to achieving sub-cellular targeting of bioactives using pharmaceutical nanocarriers. In: Prolop A, editor. Intracellular Delivery: Fundamental Biomedical Technologies. New York, NY: Springer; 2011:57-72.

126. Kruth HS, Jones NL, Huang W, et al. Macropinocytosis is the endocytic pathway that mediates macrophage foam cell formation with native low density lipoprotein. J Biol Chem. 2005;280(3):2352-2360.

127. Meier O, Boucke K, Hammer SV, et al. Adenovirus triggers macropinocytosis and endosomal leakage together with its clathrinmediated uptake. J Cell Biol. 2002;158(6):1119-1131.

128. Ungewickell EJ, Hinrichsen L. Endocytosis: clathrin-mediated membrane budding. Curr Opin Cell Biol. 2007;19(4):417-425.

129. Johnston APR, Such GK, Ng SL, Caruso F. Challenges facing colloidal delivery systems: from synthesis to the clinic. Curr Opin Colloid Interface Sci. 2011;16(3):171-181.

130. McMahon HT, Boucrot E. Molecular mechanism and physiological functions of clathrin-mediated endocytosis. Nat Rev Mol Cell Biol. 2011;12(8):517-533.

131. Pelkmans L, Helenius A. Endocytosis via caveolae. Traffic. 2002;3(5): 311-320.

132. Damm EM, Pelkmans L, Kartenbeck J, Mezzacasa A, Kurzchalia T, Helenius A. Clathrin- and caveolin-1-independent endocytosis: entry of simian virus 40 into cells devoid of caveolae. J Cell Biol. $2005 ; 168(3): 477-488$.

Drug Design, Development and Therapy

\section{Publish your work in this journal}

Drug Design, Development and Therapy is an international, peerreviewed open-access journal that spans the spectrum of drug design and development through to clinical applications. Clinical outcomes, patient safety, and programs for the development and effective, safe, and sustained use of medicines are a feature of the journal, which

has also been accepted for indexing on PubMed Central. The manuscript management system is completely online and includes a very quick and fair peer-review system, which is all easy to use. Visit http://www.dovepress.com/testimonials.php to read real quotes from published authors. 